\title{
Perencanaan Strategis Sistem Informasi dan Teknologi Informasi E-Agribusiness pada PT Trubus Yogyakarta
}

\author{
Denny Happy Utama ${ }^{1}$, Melkior N. N. Sitokdana ${ }^{2}$, Agustinus Fritz Wijaya ${ }^{3}$ \\ Program Studi Sistem Informasi, Fakultas Teknologi Informasi, Universitas Kristen Satya Wacana, \\ Jl. Dr. O. Notohamidjojo, Salatiga 50714 \\ ${ }^{1}$ 682013088@student.uksw.edu, ${ }^{2}$ sitokdanamelkior@staff.uksw.edu, ${ }^{3}$ agustinus.wijaya@uksw.edu)
}

Diterima: 8 Juli 2018 | Direvisi: 23 Juli 2018 | Disetujui: 2 Agustus 2018

\begin{abstract}
Business unit can use information technology to run its business activities. Despite utilizing information technology but PT Trubus is still slow in responding to orders from consumers online through the company website. Based on these facts, it is necessary strategic planning of information system (IS) and information technology (IT) is appropriate. The main issues in this research are how to make strategic planning of information system and information technology by using the right techniques to obtain income, and maximum financial benefit, and recommend the utilization of IS and IT in the future. The analysis used were PEST analysis, SWOT analysis, Mc Farlan Strategic Grid framework, and Ward and Peppard methodology. The results of the research is the formation of the upcoming application portfolio of mobile android based information applications, website-based information system applications, PT Trubus information system applications, SOP document applications, and SIPA applications.
\end{abstract}

Keywords: Strategic Planning, PEST, SWOT, Mc Farlan Strategic Grid

Intisari- Setiap unit usaha dapat menggunakan teknologi informasi untuk menjalankan aktivitas bisnisnya. Meskipun memanfaatkan teknologi informasi tetapi PT Trubus masih lambat dalam menanggapi pesanan dari konsumen secara online melalui website perusahaan. Berdasarkan fakta tersebut, maka diperlukan perencanaan strategis sistem informasi (SI) dan teknologi informasi (TI) yang tepat. Hal-hal yang menjadi permasalahan pokok dalam penelitian ini adalah bagaimana membuat perencanaan strategis sistem informasi dan teknologi informasi dengan menggunakan teknik-teknik yang tepat agar memperoleh pendapatan, dan keuntungan finansial yang maksimal, serta merekomendasikan pemanfaatan SI dan TI di masa mendatang. Analisis yang digunakan yaitu analisis PEST, analisis SWOT, McFarlan Strategic Grid framework, dan metodologi Ward and Peppard. Hasil penelitian yaitu terbentuknya portofolio aplikasi mendatang yaitu aplikasi informasi berbasis mobile android, aplikasi sistem informasi berbasis website, aplikasi sistem informasi PT Trubus, aplikasi dokumen SOP, dan aplikasi SIPA.

Kata kunci: Perencanaan Strategis, PEST, SWOT, Mc Farlan Strategic Grid

\section{PENDAHULUAN}

Setiap unit usaha saat ini sudah menggunakan teknologi informasi untuk menjalankan aktivitas bisnisnya, karena merupakan suatu kebutuhan yang harus dipenuhi demi memperlancar transaksi usahanya, tanpa terkecuali usaha dibidang pertanian atau dikenal dengan istilah agribisnis. Agribisnis yang kegiatan usahanya memanfaatkan teknologi informasi dikenal dengan istilah e-agribusiness. Jadi $e$ agribusiness pada dasarnya adalah pemanfaatan teknologi informasi dalam bisnis di bidang pertanian.[1] Salah satu unit usaha agribisnis yang memanfaatkan teknologi informasi ialah PT. Trubus Mitra Swadaya cabang Yogyakarta, yang merupakan toko ritel yang menjual produk pertanian seperti bibit tanaman unggul, sarana pertanian, media tanam dan pupuk, garden tools, buku pertanian, majalah dan bundel trubus, serta produk herbal.

Pemanfaatan teknologi yang dilakukan oleh PT Trubus dimaksudkan untuk mencapai tujuan utama perusahaannya yaitu memperoleh pendapatan maupun keuntungan finansial yang maksimal. Namun kenyataannya, pemanfaatan teknologi informasi untuk menunjang aktivitas bisnis tersebut kurang optimal seperti misalnya lambatnya PT Trubus dalam menanggapi pesanan dari konsumen secara online melalui website perusahaan, sehingga menyebabkan transaksi jual beli terhambat. Berdasarkan fakta tersebut, maka diperlukan perencanaan strategis sistem informasi (SI) dan teknologi informasi (TI) yang tepat. Melalui perencanaan SI dan TI yang tepat, perusahaan mampu melihat kondisi internal maupun eksternal yang terkait dengan perusahan secara objektif, sehingga dapat mengatasi, serta mengantisipasi perubahan lingkungan bisnis yang terjadi. Hal-hal yang menjadi permasalahan pokok dalam penelitian ini adalah bagaimana membuat perencanaan strategis sistem informasi dan teknologi informasi dengan menggunakan teknik-teknik seperti analisis PEST (Politik, Ekonomi, Sosial, Teknologi), analisis SWOT (Strength, Weakness, Opportunities, Threats), serta Mc Farlan 
Strategic Grid demi menunjang aktivitas bisnis maupun pencapaian tujuan perusahaan.

Penelitian ini bertujuan untuk mengetahui langkahlangkah perencanaan strategis yang menunjang kelancaran aktivitas bisnis, pencapaian tujuan perusahaan yaitu perolehan pendapatan, dan keuntungan finansial yang maksimal, serta merekomendasikan pemanfaatan SI dan TI di masa mendatang. Dalam pembuatan perencanaan strategis SI maupun TI ada beberapa kerangka pikir (framework) yang dapat digunakan yaitu framework analisis PEST, analisis SWOT serta Mc Farlan Strategic Grid framework, dengan alasan bahwa framework tersebut lebih mudah dipahami karena mempunyai framework yang jelas kondisi maupun jenis yang dijalankan oleh PT Trubus lebih cocok menggunakan Mc Farlan Strategic Grid framework, maupun analisis SWOT framework.

\section{TINJAUAN PUSTAKA}

Beberapa penelitian terdahulu yang telah dilakukan untuk membahas rencana strategis sistem informasi dan teknologi informasi antara lain: 1. Penelitian yang dilakukan oleh Kristanto pada tahun 2015 telah menemukan bahwa rekomendasi yang disempurnakan 6 sistem informasi yang sudah ada dan penambahan 6 sistem informasi baru, sehingga dapat digunakan secara maksimal untuk memenuhi kebutuhan bisnis perusahaan. [5] 2 Penelitian yang dilakukan oleh Fariani pada tahun 2014 yang menyimpulkan bahwa strategi yang dihasilkan berupa portofolio SI yang akan dibangun, gap analisis dan roadmap dari pengembangan SI/TI yang diusulkan. [6] 3 Penelitian yang dilakukan oleh Sitokdana, dan Winarno pada tahun 2015 menghasilkan temuan bahwa rencana pemerintah Provinsi Papua terkait dengan integrasi sistem informasi antara SKPD yang sudah diterapkan, pengembangan SI lebih lanjut disesuaikan dengan blueprint pengembangan $e$ government yang dikeluarkan Kominfo, serta dihasilkan roadmap rencana strategis e-government yang sejalan dengan visi Dinas Kominfo Provinsi Papua yaitu "terwujudnya Papua informatif menuju e-government serta masyarakat berbudaya informasi melalui penyelenggaraan komunikasi dan informasi yang efektif dan efisien".[7]

Analisis PEST (Politik, Ekonomi, Sosial, Teknologi) adalah analisa terhadap faktor lingkungan eksternal bisnis yang meliputi faktor politik, ekonomi, sosial, dan teknologi, yaitu:[2]

a. Faktor politik meliputi kebijakan pemerintah, masalahmasalah hukum, serta mencakup aturan-aturan formal dan informal dari lingkungan dimana perusahaan melakukan kegiatannya, seperti: kebijakan tentang pajak, peraturan ketenagakerjaan, peraturan daerah, peraturan perdagangan, serta stabilitas politik.

b. Faktor ekonomi terdiri dari semua faktor yang mempengaruhi daya beli dari konsumen atau pelanggan, dan mempengaruhi iklim berbisnis suatu perusahaan, seperti: pertumbuhan ekonomi, tingkat suku bunga, standar nilai tukar, tingkat inflasi, harga barang dan jasa.

c. Faktor sosial meliputi semua faktor yang dapat mempengaruhi kebutuhan dari pelanggan atau konsumen dan mempengaruhi ukuran dari besarnya pangsa pasar yang ada, seperti: tingkat pendidikan, tingkat pertumbuhan penduduk, kondisi lingkungan sosial, kondisi lingkungan kerja, keselamatan dan kesejahteraan sosial. d. Faktor teknologi meliputi semua hasil yang dapat membantu dalam menghadapi tantangan bisnis dan mendukung efisiensi proses bisnis, seperti: aktivitas penelitian dan pengembangan teknologi, automatisasi, kecepatan transfer teknologi, serta tingkat kadaluarsa teknologi.

Analisis SWOT (Strength, Weakness, Opportunities, Threats) digunakan untuk menilai kekuatan-kekuatan dan kelemahan-kelemahan dari sumber daya yang dimiliki perusahaan dan kesempatan-kesempatan eksternal dan tantangan-tantangan yang dihadapi. Kekuatan diidentifikasikan dengan tujuan untuk mengetahui apa saja kekuatan organisasi untuk dapat meneruskan dan mempertahankan bisnis. Dengan mengetahui kekuatan yang dimiliki, organisasi akan dapat mempertahankan dan bahkan meningkatkan kekuatan sebagai modal untuk dapat bersaing. Mengidentifikasi kelemahan bertujuan untuk dapat mengetahui apa kelemahan-kelemahan yang masih ada, dan dengan mengetahui kelemahan tersebut, maka perusahaan dapat berusaha untuk memperbaiki agar menjadi lebih baik. Kelemahan yang tidak atau terlambat teridentifikasi akan merugikan bagi perusahaan. Oleh karena itu dengan semakin cepat mengetahui kelemahan, maka perusahaan juga dapat sesegera mungkin mencari solusi untuk dapat menutupi kelemahan tersebut. Dengan mengetahui peluang, baik peluang saat ini maupun peluang dimasa yang akan datang, maka perusahaan dapat mempersiapkan diri untuk dapat mencapai peluang tersebut. Berbagai strategi dapat disiapkan lebih dini dan terencana dengan lebih baik sehingga peluang yang telah diidentifikasi dapat direalisasikan. Berbagai jalan untuk dapat mewujudkan peluang/kesempatan dan mempertahankan kelangsungan bisnis organisasi tentunya akan mengalami banyak ancaman. Ancaman yang dapat teridentifikasi dapat dicarikan jalan keluarnya sehingga organisasi dapat meminimalkan ancaman tersebut.[3]

Adapun alat yang dipakai untuk menyusun faktor-faktor strategis perusahaan adalah matrik SWOT. Matrik ini dapat menggambarkan secara jelas bagaimana peluang dan ancaman eksternal yang dihadapi perusahaan dapat disesuaikan dengan kekuatan dan kelemahan yang dimilikinya.[4] Matriks SWOT terbagi menjadi 4 kuadran yang masing-masing kuadran berisi mengenai strategi yang harus diterapkan oleh perusahaan. Analisis SWOT lebih mudah dilakukan melalui perhitungan sederhana untuk mengetahui perusahaan berada pada posisi kuadran yang mana, sehingga akan lebih mudah pula merumuskan serta menerapkan strategi yang harus dijalankan oleh perusahaan. Matrik SWOT dapat dilihat pada Tabel 1.

TABEL I MATRIK SWOT [2]

\begin{tabular}{|c|c|c|}
\hline & $\begin{array}{l}\text { Kekuatan } \\
\text { (Strength) }\end{array}$ & $\begin{array}{l}\text { Kelemahan } \\
\text { (Weakness) }\end{array}$ \\
\hline $\begin{array}{l}\text { Peluang } \\
\text { (Opportunities) }\end{array}$ & $\begin{array}{l}\text { Kuadran I } \\
\text { Strategi SO yaitu strategi } \\
\text { yang menggunakan } \\
\text { kekuatan untuk } \\
\text { memanfaatkan peluang } \\
\text { (Strategi Agresif) }\end{array}$ & $\begin{array}{l}\text { Kuadran III } \\
\text { Strategi WO yaitu strategi } \\
\text { yang meminimalkan } \\
\text { kelemahan untuk } \\
\text { memanfaatkan peluang } \\
\text { (Strategi Berbenah) }\end{array}$ \\
\hline $\begin{array}{l}\text { Ancaman } \\
\text { (Threats) }\end{array}$ & $\begin{array}{l}\text { Kuadran II } \\
\text { Strategi ST yaitu strategi } \\
\text { yang menggunakan } \\
\text { kekuatan untuk mengatasi } \\
\text { ancaman (Strategi } \\
\text { Diversifikasi) }\end{array}$ & $\begin{array}{l}\text { Kuadran IV } \\
\text { Strategi WT yaitu strategi } \\
\text { yang meminimalkan } \\
\text { kelemahan untuk } \\
\text { menghindari ancaman } \\
\text { (Strategi Defensif) }\end{array}$ \\
\hline
\end{tabular}


Setelah analisis PEST serta analisis SWOT selesai dilakukan, maka langkah selanjutnya melakukan analisa dengan teknik Mc Farlan strategic grid. Mc Farlan strategic grid digunakan untuk memetakan aplikasi SI berdasarkan konstribusinya terhadap organisasi. Pemetaan dilakukan pada empat kuadran (strategic, key operation, support and high potential).[3] Portofolio aplikasi Mc Farlan digunakan untuk menilai kontribusi SI/TI secara keseluruhan dan efeknya terhadap kesuksesan bisnis. Tabel 2 merupakan portofolio aplikasi yang menampilkan sebuah analisa dari keseluruhan aplikasi perusahaan, baik yang ada saat ini, potensial ataupun yang masih direncanakan.

TABEL II MC FARLAN STRATEGIC GRID[2]

\begin{tabular}{lll}
\hline \multicolumn{1}{c}{ Strategic } & \multicolumn{2}{c}{ High Potential } \\
\hline $\begin{array}{l}\text { Applications that are critical to } \\
\text { sustaining future business strategy }\end{array}$ & $\begin{array}{l}\text { Applications that may be } \\
\text { important in achieving future } \\
\text { success }\end{array}$ \\
\hline \multicolumn{1}{c}{ Key Operational } & \multicolumn{1}{c}{ Support } \\
\hline $\begin{array}{l}\text { Applications on which the } \\
\text { organization currently depends for } \\
\text { success }\end{array}$ & $\begin{array}{l}\text { Applications that are valuable but } \\
\text { not critical to success }\end{array}$ \\
\hline
\end{tabular}

Keterangan dari Mc Farlan strategic grid pada Tabel 2 yaitu:[2]

a. Strategic adalah aplikasi yang memiliki pengaruh kritis terhadap keberhasilan bisnis perusahaan di masa mendatang. Aplikasi strategis adalah aplikasi yang mendukung perusahaan dengan memberikan keunggulan bersaing.

b. Key Operational adalah aplikasi yang menunjang kelangsungan bisnis perusahaan. Apabila terhenti, perusahaan tidak bisa beroperasi dengan normal dan hal ini akan mengakibatkan menurunnya keunggulan perusahaan.

c. Support adalah aplikasi yang mendukung perusahaan dalam meningkatkan efisiensi bisnis dan efektifitas manajemen, namun tidak memberikan keunggulan bersaing.

d. High Potential adalah aplikasi yang mungkin dapat menciptakan peluang keunggulan bagi perusahaan di masa mendatang, tetapi masih belum terbukti.

\section{METODOLOGI PENELITIAN}

Metode penelitian yang digunakan dalam penelitian ini adalah deskriptif kualitatif. Metode deskriptif merupakan penggambaran suatu gejala sosial yang bertujuan untuk mendeskripsikan sifat objek yang diteliti. [8] Metode kualitatif bertujuan untuk menjelaskan fenomena sedalam-dalamnya tentang apa yang dialami oleh subjek penelitian secara holistik pada saat ini, yang disajikan dalam bentuk kata-kata dan bahasa melalui pengumpulan data sedalam-dalamnya [9]. Selain itu, metode ini dapat diterapkan pada berbagai masalah [10].
Penelitian ini dilakukan melalui beberapa tahap, yaitu:

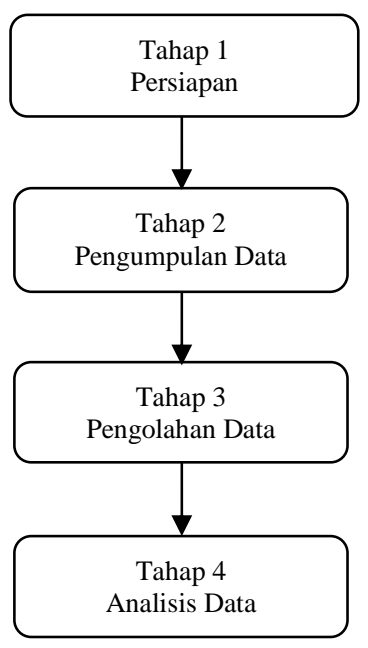

Gbr. 1. Tahapan Penelitian

Tahap 1 Persiapan. Pada tahap persiapan ini, peneliti mulai mencari serta mengumpulkan berbagai materi yang mendukung penelitian. Seluruh materi tersebut diperoleh melalui berbagai sumber referensi seperti buku teks, jurnal (jurnal nasional maupun jurnal internasional), website terpercaya maupun dokumen yang terkait dengan penelitian ini. Selanjutnya, peneliti mengurus surat ijin penelitian dari kampus di kantor Tata Usaha Fakultas Teknologi Informasi Universitas Kristen Satya Wacana, dan perijinan penelitian dari instansi pemerintah di Dinas Perijinan kota Yogyakarta di komplek kantor Walikota Yogyakarta. Pada tahap pertama dalam penelitian ini diperoleh keluaran berupa jadwal penelitian, objek dan responden penelitian, serta hal yang akan diteliti.

Tahap 2 Pengumpulan Data. Pada tahap kedua, input yang sudah ada yaitu jadwal penelitian, target responden penelitian, dan apa saja hal yang akan diteliti apabila telah mendapatkan persetujuan atau disetujui, maka peneliti dapat memulai proses pengumpulan data dengan melakukan wawancara kepada responden penelitian, serta studi pendahuluan kepada pihak terkait penelitian yang dilaksanakan pada bulan Juli 2017.

Tahap 3 Pengolahan Data. Tahap ketiga ditujukan untuk mengolah output atau keluaran yang dihasilkan pada tahap kedua yang berupa hasil wawancara. Pada tahap ini, hasil wawancara yang telah diperoleh diperiksa kembali dengan melakukan wawancara mendalam kepada responden penelitian, serta melakukan survei atau observasi lapangan secara langsung.

Tahap 4 Analisa Data. Pada tahap keempat dalam penelitian ini yaitu analisa data. Setelah diperoleh hasil pengolahan data, kemudian hasil olah data tersebut dianalisis menggunakan teknik analisis PEST, analisis SWOT, serta analisis Mc Farlan Strategic Grid.

Penggunaan metode deskriptif kualitatif dalam penelitian ini mengharuskan peneliti agar memahami secara mendalam hasil analisa data sehingga dapat menjawab permasalahan pokok dari peneltian ini, serta tujuan penelitian ini dapat dicapai dengan baik. Hal yang harus dilakukan peneliti ialah menganalisa datadata yang ada di PT Trubus terkait dengan SI maupun TI serta data-data pendukung lainnya yang berasal dari pakar. 
Jenis data yang digunakan dalam penelitian ini adalah data primer dan data sekunder. Data primer merupakan daya yang diperoleh secara langsung dari responden penelitian atau sumber data, dalam hal ini kepala cabang (Bp. Sugino), Staff IT (Riski, S.Kom), promosi website (Asmoro, S.Kom), supervisor toko (Budi Yuswanto), dan admin (Eka N.C) PT Trubus dengan melakukan wawancara mendalam. Selain dilakukan wawancara mendalam, juga dilakukan survei lapangan maupun observasi secara langsung oleh peneliti untuk pengumpulan buktinya. Sedangkan data sekunder ialah data yang diperoleh dari berbagai literatur, seperti buku teks, jurnal-jurnal baik nasional maupun internasional, website terpercaya, serta dokumen/arsip tertulis PT Trubus yang berkaitan dengan visi, misi PT Trubus dan Perencanaan Strategis Sistem Informasi dan Teknologi Informasi. Adapun visi dan misi PT Trubus sebagai berikut:

Visi dari PT Trubus adalah menjadi perusahaan agribisnis yang diakui unggul dalam produk dan jasa berkualitas tinggi.

Misi dari PT Trubus adalah:

a. Memperluas akses bagi konsumen untuk mendapatkan produk dan jasa yang dapat meningkatkan nilai tambah serta manfaat dari hobi dan kegiatan bisnis bidang pertanian.

b. Memproduksi dan menjalankan fungsi retail, serta menjadi distributor produk dan sarana pertanian.

c. Mempengaruhi kebijakan pembangunan agar lebih mendukung pengembangan produk, pemasaran produk dan sarana pertanian.

d. Memperluas jaringan pelayanan secara berkelanjutan.

\section{ANALISIS DAN PEMBAHASAN}

Penulis melakukan tahap wawancara dengan cara memilih beberapa responden yang terkait dengan penelitian ini pimpinan PT. Trubus Yogyakarta.

PT Trubus Yogyakarta didirikan sebagai dari tuntutan pembaca majalah pertanian trubus yang di terbitkan 1969 berkenaan dengan pengadaan bibit dan sarana pertanian, maka pada tahun 1983 di buka toko pertanian pertama yang terletak di jalan Gunung Sahari III/7, Jakarta Pusat yang lebih di kenal dengan nama Toko Trubus Sahari. Pada tahun yang sama dibangun toko trubus kedua yaitu Toko Trubus Cimanggis yang berlokasi di Desa Mekarsari, Cimanggis, Depok. Kegiatan Toko Trubus Cimanggis yaitu pengadaan dan perawatan tanaman yang mendukung suplai tanaman buah di Toko Trubus yang lain. Sampai saat ini Toko Trubus telah memiliki 17 Toko Trubus, yang tersebar di Jabodetabek (Cimanggis, Makro PS Rebo, Gunung Sahari, Daan Mogot, Bintaro, Cikarang, Makro Ciputat, Makro Meruya), Jawa Tengah (Semarang, Unggaran, Purwokerto), Yogyakarta, Jawa Barat (Bandung), dan Jawa Timur (Sidoarjo). Toko Trubus berkomitmen memberikan pelayanan yang terbaik bagi konsumen untuk mendapatkan produk dan jasa yang berkualitas tinggi sehingga meningkatkan nilai tambah serta manfaat dari hobiis dan kegiatan bisnis pertanian.
Analisis Framework Ward and Peppard seperti pada Gbr. 2.

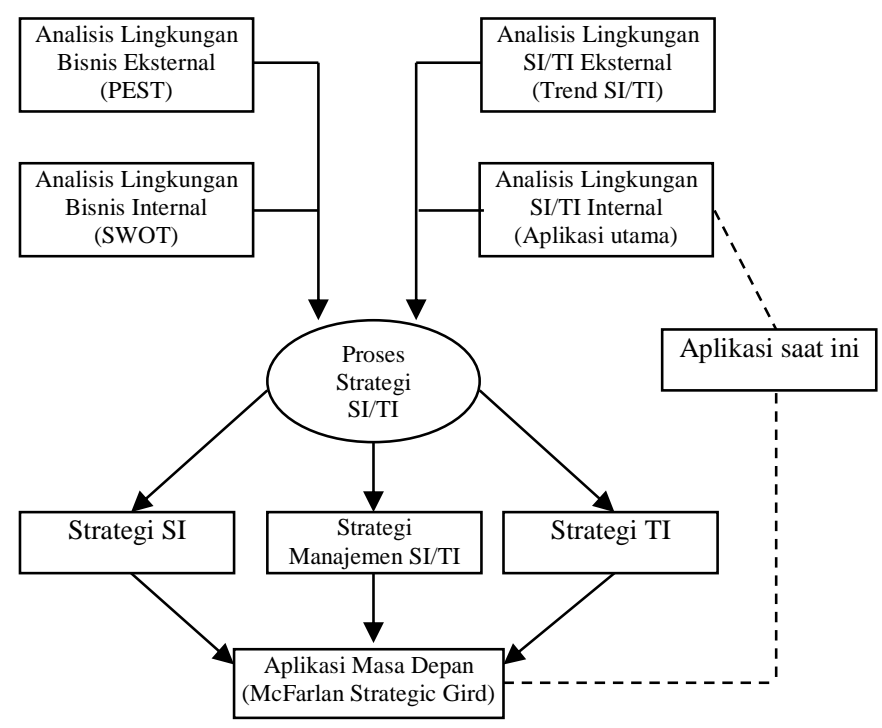

Gbr 2. Analisis Framework Ward and Peppard

Metodologi yang digunakan untuk membuat perencanaan strategis SI/TI adalah Framework Ward and Peppard. Pada pengembangan SI/TI di PT. Trubus Yogyakarta. Metodologi ini dirasa lebih lengkap dan terstruktur dibanding metodologi perencanaan strategis lainnya seperti: Metode Information Engineering versi James Martin, Metode Enterprise Architecture Planning (EAP) versi Steven H. Spewak, Metode Zachman Framework for Enterprise Architecture, Metodologi versi Tozer. Langkah-langkah yang diambil dari teknik analisis Framework Ward and Peppard untuk membuat perencanaan strategis SI/TI adalah:

a. Analisis lingkungan bisnis Eksternal dan Internal terhadap kondisi bisnis PT. Trubus Yogyakarta menggunakan teknik PEST dan SWOT.

b. Analisis lingkungan bisnis Eksternal dan Internal penggunaan SI/TI.

c. Membuat strategi SI/TI.

d. Mengembangkan aplikasi untuk masa depan perusahaan menggunakan teknik Mc Farlan Strategic Gird.[2]

\section{A. Analisis PEST}

Faktor politik yang memiliki efek pada PT Trubus Yogyakarta adalah Peraturan Menteri Pertanian Nomor 86 Tahun 2013 tentang Rekomendasi Produk Impor Hortikultura (RPIH), mengatur persyaratan teknis penerbitan RPIH dan Peraturan Menteri Perdagangan Nomor 70/MDAG/PER/12/2013 tentang Pedoman Penataan dan Pembinaan Pasar Tradisional, Pusat Perbelanjaan dan Toko Modern. Pemerintah dalam kebijakannya telah mengeluarkan dan menetapkan UU ITE atau UU No. 11 tahun 2008 yang mengatur tentang informasi serta transaksi elektronik, UU No. 19 tahun 2013 tentang perlindungan dan pemberdayaan usaha petani, serta mengeluarkan UU No. 7 tahun 2014 tentang perlindungan perdagangan dalam melakukan kegiatan bisnis melalui sistem elektronik.

Faktor ekonomi yang menjadi perhatian dari PT Trubus Yogyakarta adalah nilai tukar dolar Amerika yang sulit dikendalikan, suku bunga bank tinggi, pajak yang berlaku, 
income perkapita dan isu moneter lainnya membuat perusahaan harus dengan cermat mengantisipasinya. Namun peluang yang dapat diperoleh adalah meningkatnya jumlah dan nilai pembelian belanja konsumen, sedangkan tantangan yang dihadapi adalah penetapan harga jual barang yang harus dinamis.

Faktor sosial yang menjadi perhatian dari PT Trubus Yogyakarta adalah perkembangan jumlah penduduk, perubahan gaya hidup. Peluang yang diperoleh adalah Meningkatnya jumlah konsumen akibat peningkatan jumlah penduduk dan tantangan yang dihadapi adalah perlunya penyediaan jumlah variasi produk dan harga.

Faktor teknologi yang menjadi perhatian dari PT Trubus Yogyakarta adalah internet, mobile phone, otomasi, inovasi, akses ke teknologi, lisensi dan hak paten, manufaktur, penelitian, komunikasi global, perkembangan teknologi, biaya penelitian, ketergantungan teknologi, solusi atau perubahan teknologi, kematangan teknologi, kematangan manufaktur dan kemampuannya, informasi dan komunikasi, teknologi/mekanisme pembelian oleh pelanggan.

\section{B. Analisis SWOT}

Analisis terhadap PT Trubus Yogyakarta dengan menggunakan SWOT terangkum dalam Tabel 3.

\section{TABel III PemetaAn SWOT PT Trubus Yogyakarta}

\begin{tabular}{|c|c|c|}
\hline \multicolumn{3}{|l|}{ INTERNAL } \\
\hline & 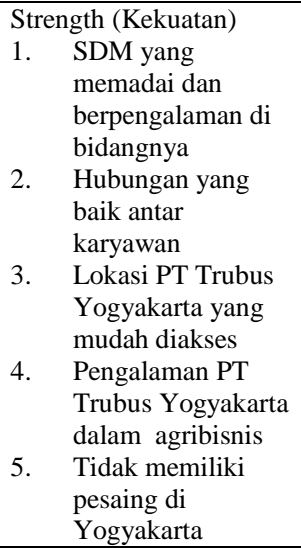 & $\begin{array}{ll}\text { Weakness } \\
\text { (Kelemahan) } \\
\text { 1. } & \begin{array}{l}\text { Infrastruktur SI } \\
\text { dan TI yang }\end{array} \\
& \text { belum maksimal } \\
\text { 2. } & \text { Jumlah admin TI } \\
& \text { yang kurang dan } \\
\text { memiliki cakupan } & \text { kerja yang terlalu } \\
& \text { luas }\end{array}$ \\
\hline \multicolumn{3}{|l|}{ EKSTERNAL } \\
\hline $\begin{array}{l}\text { Opportunities } \\
\text { (Peluang) } \\
\text { 1. Perkembangan } \\
\text { teknologi informasi } \\
\text { yang pesat } \\
\text { 2. Kepercayaan warga } \\
\text { Yogyakarta } \\
\text { terhadap kualitas PT } \\
\text { Trubus Yogyakarta } \\
\text { 3.Pengembangan } \\
\text { sistem informasi } \\
\text { untuk efektivitas } \\
\text { layanan konsumen }\end{array}$ & $\begin{array}{l}\text { Strategi SO } \\
\text { 1. Menjaga kualitas } \\
\text { SDM untuk } \\
\text { meningkatkan kualitas } \\
\text { pelayanan sehingga } \\
\text { kepercayaan } \\
\text { masyarakat terjaga } \\
\text { 2. Memanfaatkan dana } \\
\text { untuk } \\
\text { mengembangkan SI } \\
\text { dan TI } \\
\text { 3. Menerapkan } \\
\text { manajemen mutu } \\
\text { untuk menjaga } \\
\text { kualitas pelayanan }\end{array}$ & $\begin{array}{l}\text { Strategi WO } \\
\text { 1. Penyediaan } \\
\text { infrastruktur SI dan } \\
\text { TI } \\
\text { 2. Pengembangan } \\
\quad \text { website }\end{array}$ \\
\hline
\end{tabular}

\begin{tabular}{lll}
$\begin{array}{l}\text { Threats (Ancaman) } \\
\begin{array}{l}\text { 1. Keterbatasan dana } \\
\text { untuk }\end{array}\end{array}$ & $\begin{array}{l}\text { Strategi ST } \\
\text { 1. Alokasi anggaran } \\
\text { untuk SI dan TI }\end{array}$ & $\begin{array}{l}\text { 1. Penggunaan SI dan } \\
\text { TI yang lebih }\end{array}$ \\
\hline
\end{tabular}

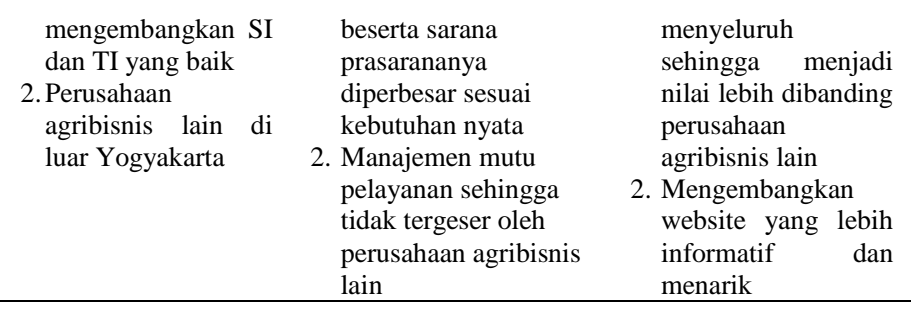

Setelah dilakukan pemetaan kondisi internal PT Trubus Yogyakarta ke dalam tabel SWOT, selanjutnya akan dilakukan penghitungan strategi analisis faktor internal (IFAS) seperti pada Tabel 4 dan strategi analisis faktor eksternal (EFAS) seperti pada Tabel 5. Hal ini dilakukan untuk mengetahui posisi kuadran PT Trubus Yogyakarta yang selanjutnya dapat digunakan untuk menyusun strategi organisasi.

\section{TABEL IV STRATEGI ANALISIS FAKTOR INTERNAL IFAS PT TRUBUS YOGYAKARTA}

\begin{tabular}{lrrc}
\hline No Faktor & Bobot & Rating & Skor \\
\hline KEKUATAN & 3 & 3 & 9 \\
$\begin{array}{l}\text { SDM yang memadai dan berpengalaman di } \\
\text { bidangnya }\end{array}$ & 2 & 2 & 4 \\
$\begin{array}{l}\text { Hubungan yang baik antar karyawan } \\
\text { Lokasi PT Trubus Yogyakarta yang mudah diakses }\end{array}$ & 1 & 3 & 3 \\
$\begin{array}{l}\text { Pengalaman PT Trubus Yogyakarta dalam } \\
\text { agribisnis }\end{array}$ & 1 & 3 & 3 \\
Tidak memiliki pesaing di Yogyakarta & 1 & 3 & 3 \\
\hline Jumlah Faktor & 8 & & 22 \\
\hline & Bobot & Rating & Skor \\
\hline No & 3 & -3 & -6 \\
\hline KELEMAHAN & & -2 & -4 \\
Infrastruktur SI dan TI yang belum maksimal & & & -10 \\
Jumlah admin TI yang kurang dan memiliki cakupan & 2 & & \\
kerja yang terlalu luas & 5 & &
\end{tabular}

Dengan catatan bahwa bobot diberikan untuk masingmasing faktor sesuai dengan tingkat kepentingan terhadap keberhasilan pencapaian tujuan. Selain itu, rating untuk Kekuatan yakni masing-masing rating tiga untuk kategori sangat bagus, dua untuk kategori bagus, dan satu untuk kategori cukup bagus. Sementara itu rating untuk Kelemahan yakni masingmasing rating minus tiga untuk kategori sangat buruk; minus dua untuk kategori buruk, dan minus satu untuk kategori cukup buruk.

TABEL V STRATEgI ANALISIS FAKTOR EKSTERNAL (EFAS) PT TRUBUS YOGYAKARTA

\begin{tabular}{|c|c|c|c|}
\hline Faktor & Bobot & Rating & Skor \\
\hline$\overline{P E L U A N G}$ & & & \\
\hline Perkembangan teknologi dan informasi yang pesat & 3 & 3 & 9 \\
\hline $\begin{array}{l}\text { Kepercayaan warga Yogyakarta terhadap kualitas } \\
\text { PT Trubus Yogyakarta }\end{array}$ & 2 & 2 & 4 \\
\hline $\begin{array}{l}\text { Pengembangan sistem informasi untuk efektivitas } \\
\text { layanan konsumen }\end{array}$ & 1 & 3 & 3 \\
\hline Jumlah & 6 & & 16 \\
\hline
\end{tabular}




\begin{tabular}{|c|c|c|c|}
\hline Faktor & Bobot & Rating & Skor \\
\hline ANCAMAN & & & \\
\hline $\begin{array}{l}\text { Keterbatasan dana untuk mengembangkan SI dan } \\
\text { TI yang baik }\end{array}$ & 2 & -3 & -6 \\
\hline Perusahaan agribisnis lain di luar Yogyakarta & 3 & -2 & -6 \\
\hline Jumlah & 5 & & -12 \\
\hline
\end{tabular}

Dengan catatan bahwa bobot diberikan untuk masingmasing elemen sesuai dengan tingkat kepentingan terhadap keberhasilan pencapaian tujuan. Rating untuk Peluang yakni masing-masing rating tiga untuk kategori sangat bagus; dua untuk kategori bagus, dan satu untuk kategori cukup bagus. Sementara itu rating untuk Ancaman yakni masing-masing rating minus tiga untuk kategori sangat buruk; minus dua untuk kategori buruk, dan minus satu untuk kategori cukup buruk.

Hasil penghitungan sederhana dari tabel IFAS dan EFAS di atas dapat diringkas dalam Tabel 6.

TABEL VI JUMLAH SKOR

\begin{tabular}{clc}
\hline No & Kuadran & Jumlah Skor \\
\hline 1 & Kekuatan & 22 \\
2 & Kelemahan & -10 \\
3 & Peluang & 16 \\
4 & Ancaman & -12 \\
\hline
\end{tabular}

Berpijak dari jumlah skor ini, maka penentuan posisi PT Trubus Yogyakarta dapat digambar sebagai Matrik SWOT yang dapat dilihat pada Gambar 3. Tetapi sebelumnya untuk mencari titik koordinat, dapat dicari dengan cara berikut:

Koordinat analisis internal (x)

Jumlah Skor Kekuatan-Jumlah Skor Kelemahan= 22-10 = 12

Koordinat analisis eksternal $(y)$

Jumlah Skor Peluang - Jumlah Skor Kelemahan $=16-12=4$

Jadi koordinat titik $(\mathrm{x}, \mathrm{y})$ ada pada titik $(12,4)$

$$
\text { Peluang }
$$

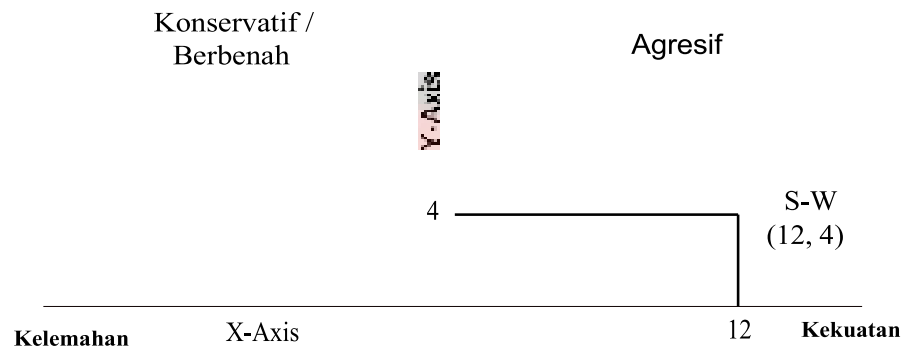

Ancaman

Gbr. 3. Matrik SWOT

\section{Analisis Lingkungan SI/TI Eksternal}

Analisis lingkungan eksternal terdiri dari ancaman pesaing baru, ancaman pesaing sesama industri dan kekuatan tawar menawar konsumen.

1. Ancaman Pesaing Baru

Pendatang baru cukup mengancam PT. Trubus Yogyakarta karena banyaknya produkproduk baru yang beredar di pasar menyebabkan banyaknya pilihan bagi para pembeli dan banyaknya produk-produk baru yang menarik tentunya mengakibatkan perusahaan kesulitan dalam penjualan di pasar.

2. Ancaman Pesaing Sesama Industri

Peluang yang dimiliki perusahaan adalah memiliki produk yang memiliki mutu tinggi dibandingkan dengan produkproduk harga setara, dan ancaman yang dimiliki perusahaan adalah banyaknya perusahaan sejenis yang menggunakan promosi gencar yang dapat mempengaruhi perusahaan secara langsung.

3. Kekuatan Tawar Menawar Konsumen

Penawaran pasti terjadi dalam proses transaksi jual beli barang namun jika terjadi penawaran yang tidak sesuai dengan perhitungan yang dibuat oleh perusahaan maka perusahaan akan menolak penawaran tersebut dan tentu berakibat kehilangan pembeli.

\section{Analisis Lingkungan SI/TI Internal}

Analisis lingkungan internal terdiri dari bagian pemasaran, operasional, keuangan dan sumber daya manusia.

1. Pemasaran

Pemasaran merupakan bagian dari perusahaan yang memiliki peran penting. Karena pendapatan perusahaan banyak atau sedikit tergantung dari pemasaran dalam memasarkan produk atau jasa. Dalam pemasaran, perusahaan melakukan analisis konsumen, penjualan produk atau jasa, penetapan harga, distribusi, penetapan harga, riset pemasaran, dan analisis biaya/keuntungan.

2. Operasional

PT. Trubus Yogyakarta memiliki divisi produksi dan operasional. Bagian produksi dan operasional berfungsi untuk melakukan kontrol produksi, melakukan pemangkasan terhadap biaya operasi yang tidak diperlukan dalam proses produksi, mengelola dan meningkatkan efektivitas dan efisiensi operasional perusahaan

3. Keuangan

Divisi keuangan pada PT. Trubus Yogyakarta bertugas untuk melakukan pembayaran serta penganggaran keuangan. Pembayaran tersebut meliputi pembayaran kepada supplier, gaji karyawan, serta pengeluaran perusahaan yang terkait dengan operasional.

4. Sumber Daya Manusia

PT. Trubus Yogyakarta memerlukan sumber daya manusia untuk melakukan kegiatan perusahaan. PT. Trubus Yogyakarta memiliki dua macam pekerja, yakni pekerja tetap dan pekerja kontrak.

\section{E. Strategi SI/TI Eksternal}

Perkembangan jaringan komputer juga diimbangi oleh perkembangan aplikasi dan database yang seiring dengan perkembangan jaringan komputer itu sendiri. Dimulai dari aplikasi yang hanya berjalan secara stand alone hingga sekarang 
menjadi aplikasi yang dapat bekerja multi user, bahkan dapat berjalan dalam web base, konsekuensi yang harus ditanggung adalah meningkatnya kebutuhan dan untuk memanfaatkan teknologi internet secara maksimal. Tidak hanya internet, aplikasi SI dan database berbasis web ini juga telah diterapkan pada intranet dan ekstranet, sesuai dengan kebutuhan internal organisasi.

\section{F. Strategi SI/TI Internal}

Strategi SI/TI internal dari organisasi dilakukan guna mendapatkan gambaran SI PT. Trubus Yogyakarta saat ini. Ada lima infrastruktur SI/TI, yaitu Computer Hardware atau perangkat keras komputer, General Purpose Software atau perangkat lunak yang umum digunakan, Networks and Communications Facilities atau fasilitas jaringan dan komunikasi, Database (basisdata), dan Information Management Personnel atau personil manjemen informasi.

\section{G. Sistem Informasi E-Agribusiness Saat Ini}

Sistem informasi yang ada di PT Trubus belum optimal, hal ini terlihat masih banyak kendala dalam menerapkan $E$ Agribusiness. Strategi SI/TI belum selaras dengan strategi bisnis yang sekarang diterapkan. Para konsumen kebanyakan masih melakukan transaksi pembelian dengan datang langsung ke lokasi. Terkadang hasil foto produk yang terpapar di website berbeda kualitasnya di lapangan. Kurangnya pemerataan infrastruktur SI/TI seperti pada perangkat lunak (software) untuk membuat sistem $E$-Agribusiness dan minimya akses sambungan fasilitas jaringan internet di berbagai cabang toko Trubus. Belum membuat perencanaan strategis sistem informasi dan teknologi informasi dalam menunjang strategis bisnis menghadapi persaingan dan kinerja masa depan perusahaan agribisnis. Kurang optimalnya komunikasi dengan manajemen puncak perihal kondisi lokasi produksi dan pemasaran yang letaknya tersebar sehingga sistem informasi tidak terakreditasi. Tidak adanya penyelarasan antara perencanaan strategi bisnis dengan perencanaan strategis sistem informasi dan teknologi informasi agar mencapai visi dan misi perusahaan.

\section{TABEL VII $\boldsymbol{E}$-AGRIBUSINESS SAAT INI}

\begin{tabular}{ll}
\hline SI E-Agribusiness & Keterangan \\
\hline Sistem Perencanaan Pembangunan & Belum optimal \\
Sistem Pengelolaan Aset & Belum optimal \\
Sistem Pengelolaan Barang Masuk Keluar & Belum optimal \\
Website & Optimal \\
Webmail & Belum optimal \\
Sistem Infomasi Kearsipan & Belum optimal \\
Sistem Informasi Keuangan & Belum optimal \\
Sistem Informasi Kepegawaian & Belum optimal \\
\hline
\end{tabular}

\section{H. Analisis Portofolio Sistem Informasi}

Analisis digunakan untuk melihat aspek Sistem Informasi E-Agribusiness yang selama ini digunakan PT Trubus Yogyakarta. Metode McFarlan digunakan untuk memetakan aplikasi serta sistem informasi yang digunakan. Hasil pemetaan diperoleh hasil sebagai berikut:
TABEL VIII PORTOFOLIO SISTEM INFORMASI SAAT INI

\begin{tabular}{ll}
\hline High Potential & Strategic \\
\hline Sistem Perencanaan Pembangunan & Sistem informasi kearsipan \\
\hline Key Operational & Support \\
\hline Sistem Informasi Keuangan & Website \\
Sistem Informasi Kepegawaian & Webmail \\
Sistem Pengelolaan Aset & \\
Sistem pengelolaan barang masuk & \\
keluar & \\
\hline
\end{tabular}

Portofolio sistem informasi tersebut di atas diisi oleh Supervisor. McFarlan menyatakan aplikasi TI yang digunakan dalam perusahaan tidak selamanya berada pada kuadran yang sama. Suatu saat apabila aplikasi tersebut telah berkurang dampak strategisnya, maka aplikasi tersebut akan bergeser ke kuadran lain. Pergeseran dari sistem aplikasi pada teori McFarlan ini tidak bisa terjadi secara serta merta. Pergeseran aplikasi yang digunakan dalam organisasi terjadi seketika ada perubahan situasi dan kondisi umum yang dihadapi.

\section{Aplikasi Masa Depan}

Kebutuhan aplikasi sistem informasi PT. Trubus Yogyakarta adalah:

TABEl IX KebUtuhan Aplikasi

\begin{tabular}{|c|c|c|}
\hline No & Pengguna & Aplikasi Sistem Informasi \\
\hline 1 & Direktur Utama & $\begin{array}{l}\text { Aplikasi Sistem Infomasi Trubus (SIT) } \\
\text { Aplikasi Standar Operation Prosedur (SOP) }\end{array}$ \\
\hline 2 & Manajer Utama & $\begin{array}{l}\text { Aplikasi Sistem Infomasi Trubus (SIT) } \\
\text { Aplikasi Standar Operation Prosedur (SOP) }\end{array}$ \\
\hline 3 & Bagian Kepegawaian & $\begin{array}{l}\text { Aplikasi Sistem Infomasi Trubus (SIT) } \\
\text { Aplikasi Standar Operation Prosedur (SOP) }\end{array}$ \\
\hline 4 & Bagian Logistik & $\begin{array}{l}\text { Aplikasi Sistem Infomasi Trubus (SIT) } \\
\text { Aplikasi Standar Operation Prosedur (SOP) }\end{array}$ \\
\hline 5 & Bagian Marketing & $\begin{array}{l}\text { Aplikasi Sistem Infomasi Trubus (SIT) } \\
\text { Aplikasi Standar Operation Prosedur (SOP) }\end{array}$ \\
\hline 6 & $\begin{array}{l}\text { Bagian Techical } \\
\text { Support }\end{array}$ & $\begin{array}{l}\text { Aplikasi Sistem Infomasi Trubus (SIT) } \\
\text { Aplikasi Standar Operation Prosedur (SOP) } \\
\text { Aplikasi Berbasis Mobile }\end{array}$ \\
\hline
\end{tabular}

TABEL X KEBUTUHAN TEKNOLOGI INFORMASI

\begin{tabular}{|c|c|c|}
\hline No & $\begin{array}{l}\text { Kebutuhan } \\
\text { Informasi }\end{array}$ & Keterangan \\
\hline 1 & $\begin{array}{l}\text { Server yang dapat } \\
\text { beroperasi } 24 \text { jam }\end{array}$ & $\begin{array}{l}\text { Agar dapat diakses setiap saat dan } \\
\text { mampu melayani berbagai aplikasi } \\
\text { berbasis website dan lokal }\end{array}$ \\
\hline 2 & $\begin{array}{l}\text { Penambahan beberapa } \\
\text { komputer dan printer untuk } \\
\text { tiap bagian }\end{array}$ & $\begin{array}{l}\text { Agar tiap bagian dapat melakukan } \\
\text { kegiatan operasional }\end{array}$ \\
\hline 3 & $\begin{array}{l}\text { Peningkatan jaringan } \\
\text { wireless yang sudah ada }\end{array}$ & $\begin{array}{l}\text { Agar dapat menjamin kecepatan akses } \\
\text { internet }\end{array}$ \\
\hline 4 & Penambahan wireless & $\begin{array}{l}\text { Agar jaringan internet lebih luas dan } \\
\text { dapat diakses di lingkungan } \\
\text { perusahaan }\end{array}$ \\
\hline 5 & $\begin{array}{l}\text { Pengadaan perangkat } \\
\text { mobile }\end{array}$ & $\begin{array}{l}\text { Agar informasi dapat tersampaikan } \\
\text { melalui media mobile }\end{array}$ \\
\hline 6 & $\begin{array}{l}\text { Penambahan absensi } \\
\text { fingerprint }\end{array}$ & $\begin{array}{l}\text { Agar memaksimalkan tingkat } \\
\text { kehadiran pegawai }\end{array}$ \\
\hline
\end{tabular}




\section{TABEL XI RENCANA STRATEgI}

\begin{tabular}{|c|c|c|c|c|c|}
\hline No & Perencanaan & 2018 & 2019 & 2020 & 2021 \\
\hline \multirow[t]{11}{*}{1} & Aplikasi Sistem Informasi PT. & & & & \\
\hline & Trubus & & & & \\
\hline & Aplikasi kepegawaian & & & & \\
\hline & Aplikasi pendataan pelanggan & & & & \\
\hline & Aplikasi administrasi dan & & & & \\
\hline & keuangan & & & & \\
\hline & Aplikasi absensi pegawai & & & & \\
\hline & Aplikasi pembelian dan penjualan & & & & \\
\hline & Aplikasi Dokumen SOP & & & & \\
\hline & Aplikasi SIPA (Sistem Informasi & & & & \\
\hline & Pengelolaan Aset) & & & & \\
\hline \multirow[t]{7}{*}{2.} & Aplikasi informasi berbasis & & & & \\
\hline & 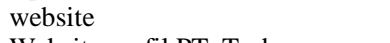 & & & & \\
\hline & Website profil PT. Trubus & & & & \\
\hline & Aplikasi chatting & & & & \\
\hline & Aplikasi e-order & & & & \\
\hline & Aplikasi mobile android & & & & \\
\hline & Aplikasi jadwal logistik & & & & \\
\hline \multirow[t]{9}{*}{3.} & Aplikasi informasi berbasis & & & & \\
\hline & Website profil PT. Trubus & & & & \\
\hline & Aplikasi chatting & & & & \\
\hline & Aplikasi e-order & & & & \\
\hline & Aplikasi mobile android & & & & \\
\hline & Aplikasi jadwal logistik & & & & \\
\hline & Aplikasi SIPA (Sistem Informasi & & & & \\
\hline & Pengelolaan Aset) & & & & \\
\hline & Aplikasi Dokumen SOP & & & & \\
\hline \multirow[t]{9}{*}{4.} & Aplikasi informasi berbasis & & & & \\
\hline & mobile android & & & & \\
\hline & Aplikasi e-order & & & & \\
\hline & Aplikasi jadwal logistik & & & & \\
\hline & Aplikasi informasi berbasis & & & & \\
\hline & website & & & & \\
\hline & Website profil PT. Trubus & & & & \\
\hline & Aplikasi chatting & & & & \\
\hline & Aplikasi e-order & & & & \\
\hline
\end{tabular}

\section{KESIMPULAN}

Berdasarkan hasil penelitian yang penulis lakukan maka dapat disimpulkan bahwa: 1) Analisis yang dilakukan dalam penelitian ini meliputi: analisis PEST, analisis SWOT, analisis lingkungan bisnis internal dan eksternal, analisis lingkungan SI/TI internal dan eksternal, dan aplikasi masa depan; 2) Tersusunnya strategi dari penelitian ini berupa perumusan kebutuhan aplikasi atau sistem informasi, perumusan kebutuhan teknologi informasi; 3) Terbentuknya portofolio aplikasi mendatang sebagai hasil akhir dari penelitian meliputi: a) Pemetaan kuadran strategic: aplikasi informasi berbasis mobile android, aplikasi sistem informasi berbasis website; b) Pemetaan kuadran key operational: aplikasi sistem informasi PT Trubus, aplikasi dokumen SOP, aplikasi SIPA; c) Pemetaan kuadran high potential: aplikasi informasi berbasis website, aplikasi mobile android, aplikasi SIPA, aplikasi dokumen SOP; d) Pemetaan kuadran support: aplikasi informasi berbasis website, aplikasi mobile android.

\section{UCAPAN TERIMA KASIH}

Terima kasih disampaikan kepada PT. Trubus Yogyakarta yang telah memberikan izin dilaksanakannya penelitian di perusahaan tersebut.

\section{REFERENSI}

[1] Soekartawi, 2007, e-Agribisnis: Teori dan Aplikasinya. Seminar Nasional Aplikasi Teknologi Informasi: 19-25.

[2] Ward, J., \& Peppard, J., 2002, Strategic Planning for Information Sistems. West Sussex: John Wiley \& Sons Limited.

[3] Wedhasmara, A., 2009, Langkah-langkah Perencanaan Strategis Sistem Informasi Dengan Menggunakan Metode Ward dan Peppard. Jurnal Sistem Informasi (JSI), Vol.1(1): 14-22.

[4] Jogiyanto, H.M., 2005, Sistem Informasi Strategik, Yogyakarta: Andi Offset.

[5] Kristanto, Titus, 2015, Perencanaan Strategis Sistem Informasi Dan Teknologi Informasi Pada PT Adira Dinamika Multi Finance, Seminar Nasional Sistem Informasi Indonesia: 1-8.

[6] Fariani, Rida Indah, 2014, Analisa Perencanaan Strategis Sistem Informasi Dan Teknologi Informasi (SI/TI) Menggunakan Framework Wark \& Peppard, Seminar Nasional Sistem Informasi Indonesia: 61-67.

[7] Sitokdana, M.N.N., dan Winarno, W.W., 2015. Rencana Strategis E-Government di Provinsi Papua. Seminar Nasional Teknologi Informasi dan Multimedia 2015 STIMIK AMIKOM Yogyakarta: 25-30

[8] Maman, Kh., 2002, Menggabungkan Metode Penelitian Kuantitatif dengan Kualitatif, Bogor: Institut Pertanian Bogor.

[9] Moleong, L., J, 2011, Metodologi Penelitian Kualitatif. Bandung: PT Remaja Rosdakarya.

[10]Husein, Umar, 1999, Metodologi Penelitian: Aplikasi dalam Pemasaran, Jakarta: Gramedia. 